\title{
Pharmacokinetics and pharmacodynamics of sotalol in a pediatric population with supraventricular and ventricular tachyarrhythmia
}

\begin{abstract}
Objective: This pharmacokinetic-pharmacodynamic study was designed to define the steady-state relationship between pharmacologic response and dose or concentration of sotalol in children with cardiac arrhythmias, with an emphasis on neonates and infants.

Methods: The treatment consisted of an upward titration with unit doses of 10,30 , and $70 \mathrm{mg}$ of sotalol per square meter of body surface area. The patients received 3 doses at each dose level. The dosing interval was 8 hours. The Class III and $\beta$-blocking activities of sotalol were derived from the QT and R-R intervals, respectively, of the surface electrocardiogram, which was recorded at 6 scheduled times before and after the third, sixth, and ninth doses. During these three dose intervals, 4 scheduled blood samples were also collected. Drug concentrations were measured with a validated nonstereoselective liquid chromatographic tandem mass spectrometric detection assay. Pharmacokinetic and pharmacodynamic parameters were obtained with standard methods.

Results: Twenty-one centers enrolled 25 patients in the study: 7 were neonates, 9 were infants, and 11 were children between the ages of 2 years and 12 years. The area under the drug concentration-time curve increased proportionately with dose. The apparent oral clearance of sotalol was linearly correlated with body surface area and creatinine clearance. The smallest children (body surface area $<0.33 \mathrm{~m}^{2}$ ) displayed greater drug exposure than the larger children. The increase of QTc and R-R intervals was dose dependent. At the $70-\mathrm{mg} / \mathrm{m}^{2}$ dose level, the mean ( \pm standard deviation) maximum increase for the QTc interval was $14 \% \pm 7 \%$ and the average Class III effect during a dose interval was $7 \% \pm 5 \%$. At the same dose level, the mean maximum increase of the $R-R$ interval was $25 \% \pm 15 \%$ and the average $\beta$-blocking effect during a dose interval was $12 \% \pm 13 \%$. The effects tended to be larger in the smallest children. The Class III response and the plasma concentrations of sotalol were linearly related. The treatment was well tolerated.

Conclusions: The steady-state pharmacokinetics of sotalol were dose proportionate. Pharmacologically important $\beta$-blocking effects were observed at the $30-\mathrm{mg} / \mathrm{m}^{2}$ and $70-\mathrm{mg} / \mathrm{m}^{2}$ dose levels. Important Class III effects were seen at the $70-\mathrm{mg} / \mathrm{m}^{2}$ dose level. The Class III effect was linearly related to the drug concentration. (Clin Pharmacol Ther 2001;69:145-57.)
\end{abstract}

J. Philip Saul, MD, Bertrand Ross, MD, Michael S. Schaffer, MD, Lee Beerman, MD, Armen P. Melikian, PhD, PharmD, Jun Shi, MD, John Williams, MD, Jean T. Barbey, MD, Judy Jin, PhD, Peter H. Hinderling, $\mathrm{MD}, \mathrm{PhD}$, and the Pediatric Sotalol Investigators* Charleston, SC, Norfolk, Va, Denver, Colo, Pittsburgh, Pa, Washington, DC, and Montville, NJ

From the Children's Heart Center, Medical University of South Carolina, Charleston; Children's Hospital of the King's Daughter, Norfolk; The Children's Hospital, Denver; Children's Hospital, Pittsburgh; and the Clinical Pharmacology Department, Berlex Laboratories Inc, Montville.

*See end of text for complete list of the Pediatric Sotalol Investigators. Supported by Berlex Laboratories, Inc, Montville, NJ.

Received for publication June 19, 2000; accepted Dec 12, 2000.
Reprint requests: Peter H. Hinderling, MD, PhD, Department of Clinical Pharmacology, Berlex Laboratories, Inc, 340 Changebridge Road, P.O.Box 1000, Montville, NJ 07045-1000.

E-mail: Peter_Hinderling@berlex.com

Copyright $\odot 2001$ by Mosby, Inc.

0009-9236/2001/\$35.00 + $0 \quad \mathbf{1 3 / 1 / 1 1 3 7 9 5}$

doi:10.1067/mcp.2001.113795 
The Class III antiarrhythmic sotalol that elicits Class III and nonspecific $\beta$-blocking activity has been used in children for indications similar to those in adults. ${ }^{1-6}$ In adult subjects, the pharmacokinetics of sotalol are characterized by dose proportionality, renal excretion of the unchanged drug as the major route of elimination, lack of metabolism, and negligible plasma protein binding. 7,8

The goal of this prospective, multiple-dose pharmacokinetic-pharmacodynamic study was to define the pharmacokinetics and the relationship between the pharmacologic effects and dose or drug concentrations for sotalol in at least 2 of the youngest pediatric age groups, neonates and infants, with supraventricular tachyarrhythmia (SVT) or ventricular tachyarrhythmia (VT). In another single-dose pharmacokinetic study, the pharmacokinetics were determined in the following 4 age categories: neonates (0-30 days), infants ( $>1$ month-2 years), preschool children ( $>2-<7$ years), and school children ( $7-12$ years). ${ }^{9}$

\section{METHODS}

Design and treatment. The treatment consisted of an upward titration with the use of 3 dose levels with unit doses of 10,30 , and $70 \mathrm{mg} / \mathrm{m}^{2}$ administered every 8 hours and corresponding to daily doses of 30,90 , and $210 \mathrm{mg} / \mathrm{m}^{2}$. The patients received 3 doses at each dose level. Depending on tolerability, the dose was titrated upward every fourth dose.

The 3 dose levels chosen left sufficient spread between them. The intermediate dose level of 90 $\mathrm{mg} / \mathrm{m}^{2} / \mathrm{d}$ was derived from the initial daily dose of 160 $\mathrm{mg}$ defined in the package inserts for adults, with the assumption of an adult body surface area (BSA) of 1.73 $\mathrm{m}^{2}{ }^{1,6}$ This dose was expected to generate some measurable $\beta$-blocking activity and little Class III activity in the pediatric population. The highest daily dose level selected $\left(210 \mathrm{mg} / \mathrm{m}^{2}\right)$ was considered to be the highest safe dose in children, and pharmacologically significant prolongations of the QTc and R-R intervals were anticipated. Pharmacologically important effects were not expected after the lowest daily dose of $30 \mathrm{mg} / \mathrm{m}^{2}$. On consideration of reported break-through arrhythmias in children receiving the adult regimen of every 12 hours and to decrease the fluctuation of the drug concentrations in the pediatric population, a regimen of every 8 hours was used. ${ }^{4}$

Pediatric patients of any sex or race with an age between birth and 12 years with SVT or VT and who required therapy were eligible for participation in the study. Excluded were patients with low body weight $(<2.0$ $\mathrm{kg}$ ), patients with advanced congestive heart failure (New
York Heart Association [NYHA] Class III or IV), patients with significant diseases of organ systems other than the heart that could interfere with conduct or outcome of the study, patients with renal impairment (creatinine clearance $\leq 0.80$ of normal value for age), those with hypotension, those with bradycardia, those with bronchial asthma, those with acquired or inherited long QT syndrome, patients with uncorrected hypokalemia, hypomagnesemia, or hypocalcemia, patients with anemia, patients undergoing concomitant therapy with $\beta$-blocking agents or antiarrhythmics (excluding digoxin and adenosine) or drugs prolonging the QT interval, and patients undergoing therapy with oral or intravenous amiodarone for more than 3 days within the 3 months before the start of the study. In the event of an arrhythmia occurrence, adenosine could be administered for conversion. External direct current cardioversion and pacing cardioversion could also be performed if necessary to convert to sinus rhythm.

The patients were hospitalized during the study. The doses were normalized for BSA and administered as an extemporaneously compounded syrup formulation prepared by dissolving the tablets of sotalol. The doses were given by means of graduated syringes, and the contents were carefully squirted into the mouths of the patients. Swallowing of the syrup was supervised. After the dose of sotalol, the patients received 25 to $50 \mathrm{~mL}$ of a clear liquid of ambient temperature orally. Xanthine-containing food and beverages were not permitted from 48 hours before the administration of sotalol to the end of the study periods. No liquid or solid food was to be consumed 30 minutes before dosing until 30 minutes after the dose. Fluids were allowed ad libitum. No strenuous physical activity was permitted during the study periods.

Safety assessment included monitoring for adverse events (AEs), for clinical laboratory evaluation, and for vital signs; a complete physical examination; measurement of the body temperature, blood pressure, and heart rate; a 12-lead electrocardiogram (ECG); and hematology, biochemistry, and urinalysis evaluations. In addition, the ECG of each patient was monitored telemetrically until at least 8 hours after the last dose. Except for infants, blood pressure was measured with the patients in the supine position after the they had rested quietly for 10 minutes. Blood pressure and heart rate were also measured just before each dose and 2 hours after dosing. Height and body weight were measured at screening and just before dosing for computation of BSA.

The study was conducted in accordance with the principles of the Declaration of Helsinki and subsequent amendments. The institutional review boards of all participating investigational centers reviewed 
and approved the study protocols. The parents or guardians and the participating child, as appropriate, gave informed consent.

Procedures. The first dose of sotalol was administered to the children at 4:00 PM. Subsequent doses were given in 8-hour intervals. Blood samples were collected at $0.5,2,4$, and 8 hours, and ECGs were recorded at 0.5, $1.5,2,3,4$, and 8 hours after the third, sixth, and ninth doses. Blood samples for pharmacokinetic assessment were centrifuged at $1000 \mathrm{~g}$ to $3000 \mathrm{~g}$ for 15 minutes within 15 minutes after collection, and the separated plasma was pipetted into screw-capped polypropylene microtubes. The plasma samples were kept at $-20^{\circ} \mathrm{C}$ until analysis.

Surface electrocardiographic tracings and blood samples were collected at scheduled times. The ECGs were recorded with the patients resting. Baseline QT and R-R intervals were determined over a 7.5-hour time interval between 8:00 AM and 4:00 PM on the first study day.

Analytical method. Plasma concentrations of sotalol were determined by a validated nonstereoselective liquid chromatographic method with tandem mass spectrometric detection. $10 *$ In brief, the method used albuterol as internal standard and a C-18 solid phase extraction with $2 \%$ formic acid in methanol as the eluating solvent. The organic extract was evaporated under nitrogen to dryness, and the residue was reconstituted in $10 \%$ methanol in HPLC water and then injected into the liquid chromatography tandem mass spectrometry system. The drug and the internal standard were separated by a reverse-phase liquid chromatography. A Sciex API 365 or 3000 tandem mass spectrometer equipped with a heated nebulizer was operated in the positive ion mode. Multiple reaction monitoring with the use of the parent $\rightarrow$ daughter ion combinations of $\mathrm{m} / \mathrm{z} 273 \rightarrow 213$ and $240 \rightarrow 148$ was used to quantify sotalol and the internal standard, respectively. The recoveries of sotalol and albuterol (INN, salbutamol) were approximately $90 \%$ and $89 \%$, respectively. The method was validated in the plasma concentration range of 1 to $500 \mathrm{ng} / \mathrm{mL}$ with adequate assay precision and accuracy. The interassay variation ranged from $8.1 \%$ to $11.5 \%$, and the accuracy ranged from $2.5 \%$ to $5.7 \%$. Appropriate dilution quality-control samples were prepared and run with diluted samples. On the basis of the extraction of $0.05 \mathrm{~mL}$ of plasma, the limit of quantification was set to $1 \mathrm{ng} / \mathrm{mL}$. A typical analytical run consisted of quality-control standards, calibration standards, and matrix blanks with internal standard added.

*Summary of findings is available on request.
Data analysis. The pharmacokinetic and pharmacodynamic parameters were obtained in accordance with standard compartment model independent methods.

Pharmacokinetics. The following pharmacokinetic parameters of sotalol were determined at each of the three dose levels: the nominal maximum steady-state drug concentration measured 2 hours after administration $\left(\mathrm{C}_{\max }^{\mathrm{SS}}\right)$, the nominal minimum steady-state drug concentration measured 8 hours after administration, the area under the drug concentration-time curve $\left(\mathrm{AUC}^{\mathrm{ss}}\right)$, the apparent oral clearance $(\mathrm{Cl} / \mathrm{F})$, the average drug concentration during a dose interval $\left(\mathrm{C}_{\mathrm{ave}}^{\mathrm{sS}}\right)$, and the fluctuation factor. The AUCss was computed for the time interval of 0.5 to 8.0 hours after administration with the use of the linear trapezoidal rule. Truncated areas measured over time intervals of less than 7.5 hours were also computed when individual plasma concentration values were missing. The $\mathrm{Cl} / \mathrm{F}$ was obtained from the following equation:

$$
\mathrm{Cl} / \mathrm{F}=\mathrm{D} / \mathrm{AUC}^{\mathrm{ss}}
$$

in which $\mathrm{D}$ is the dose. $\mathrm{C}_{\mathrm{ave}}^{\mathrm{ss}}$ was obtained from the following equation:

$$
\mathrm{C}_{\mathrm{ave}}^{\mathrm{ss}}=\mathrm{AUC} \mathrm{As}^{\mathrm{ss}} / 7.5 \text { hours }
$$

The fluction factor values were calculated from the ratio of the $\mathrm{C}_{\max }^{\mathrm{ss}}$ values to the nominal minimum steady-state drug concentration values.

Creatinine clearance $\left(\mathrm{CL}_{\mathrm{CR}}\right)$ was computed from the following equation:

$$
\mathrm{K} \times \text { height }(\mathrm{cm}) / \text { serum creatinine concentration }(\mathrm{mg} / \mathrm{dL})
$$

in which $\mathrm{K}$ equals 0.45 for patients who were younger than 1 year and 0.55 for patients who were 1 year and older. ${ }^{11}$ Body surface area was computed from the following equation ${ }^{12}$ :

$$
\text { BSA }\left(\mathrm{m}^{2}\right)=\sqrt{(\text { height }(\mathrm{cm}) \times \mathrm{BW}(\mathrm{kg}) / 3600) \cdot}{ }^{12}
$$

Pharmacodynamics. The mean QT and R-R intervals were determined from 3 to 5 consecutive sinus beats at each recording time. The QTc interval was obtained from the Bazett's formula ${ }^{13}(\mathrm{QTcB}=\mathrm{QT} \times$ $\left.\mathrm{R}-\mathrm{R}^{-1 / 2}\right)$ or Fridericia's formula ${ }^{14}(\mathrm{QTcF}=\mathrm{QT} \times$ $\mathrm{R}-\mathrm{R}^{-1 / 3}$ ), in which QTc and QT are in milliseconds and $\mathrm{R}-\mathrm{R}$ is in seconds.

The following pharmacodynamic parameters were obtained: the respective areas under the QTc or R-R interval versus time curves at baseline (AUE ${ }^{b}$ ) and after drug administration measured during the third, sixth, and ninth dose interval at each dose level (AUEss). The values for $\mathrm{AUE}^{\mathrm{b}}$ and $\mathrm{AUE}^{\mathrm{ss}}$ were computed over a time interval of 7.5 hours between 8:30 AM and 4:00 PM. 
Truncated areas measured over time intervals smaller than 7.5 hours were also computed when values were missing. Baseline corrected values were obtained from the following equations:

$$
\begin{gathered}
\Delta \mathrm{AUE}^{\mathrm{ss}}=\mathrm{AUE}^{\mathrm{ss}}-\mathrm{AUE}^{\mathrm{b}} \\
\% \Delta \mathrm{AUE}^{\mathrm{ss}}=100 \times\left(\mathrm{AUE}^{\mathrm{ss}}-\mathrm{AUE}^{\mathrm{b}}\right) / \mathrm{AUE}^{\mathrm{b}}
\end{gathered}
$$

The respective observed maximum effect on the QTc or R-R interval ( $\mathrm{E}_{\max }^{\mathrm{SS}}$ ) and the corresponding time $\left(\mathrm{tE} \mathrm{E}_{\max }^{\mathrm{SS}}\right)$ were read off the effect versus time listings. The nominal minimum effect value was measured 8 hours after drug administration ( $\left.\mathrm{E}_{\mathrm{min}}^{\mathrm{sS}}\right)$. Baseline corrected values were computed for $\mathrm{E}_{\max }^{\mathrm{SS}}$ (ie, $\Delta \mathrm{E}_{\max }^{\mathrm{SS}}$ and $\% \Delta \mathrm{E}_{\max }^{\mathrm{ss}}$ ) and for $\mathrm{E}_{\min }^{\mathrm{ss}}$ (ie, $\Delta \mathrm{E}_{\min }^{\mathrm{sS}}$ and $\% \Delta \mathrm{E}_{\min }^{\mathrm{sS}}$ ) as described for AUEss. The average effect on the QTc or $\mathrm{R}-\mathrm{R}$ interval during a dose interval was estimated from the following equation:

$$
\mathrm{E}_{\mathrm{ave}}^{\mathrm{ss}}=\mathrm{AUE} \mathrm{Es}^{\mathrm{ss}} / 7.5 \text { hours }
$$

in which $\mathrm{E}_{\mathrm{ave}}^{\mathrm{ss}}$ is the average effect. Similarly, the respective average QTc and R-R interval during a corresponding time interval at baseline was computed from the following equation:

$$
\mathrm{E}_{\mathrm{ave}}^{\mathrm{b}}=\mathrm{AUE}^{\mathrm{b}} / 7.5 \text { hours }
$$

in which $\mathrm{E}_{\mathrm{ave}}^{\mathrm{b}}$ is the average QTc or R-R interval duration at baseline. A value for $\triangle \mathrm{AUE}^{\mathrm{ss}}$ of more than $5 \%$ was considered to indicate an important Class III or $\beta$-blocking effect. As in adults, the occurrence of excessive effects of sotalol on the QTc interval was evaluated in the pediatric patients with determination of the number of individuals with QTcB intervals that exceeded $525 \mathrm{~ms}$ or $\Delta \mathrm{QTcB}$ that exceeded $60 \mathrm{~ms}$ at the different dose levels. ${ }^{1}$

All of the ECGs were recorded by the same electrocardiograph model with each institution using the same machine (Schiller Model AT2 PLUS; Schiller AG, Dietikon, Switzerland). The measurements were taken after a rest period of 10 minutes with the patients in a supine position with the use of a chart speed of $50 \mathrm{~mm} / \mathrm{s}$ and an amplitude of $10 \mathrm{~mm} / \mathrm{mV}$. The electrocardiographic data were blinded on site by placement of a coded label on each recording; this ensured that all information, including the date and time obtained, was covered. The recordings were read by a single technician and reviewed by a cardiologist to determine suitability for QT and R-R interval measurement. Lead II was used for all measurements except for the occasional case when it was necessary to use another lead for technical reasons. R-R intervals were used for 2 purposes: to correct the QT interval for changes in the heart rate and to evaluate sinus node activity. Tracings with irregular R-R intervals (inter-beat variation $\Delta \mathrm{R}-\mathrm{R}>10 \%$ in a single recording) were excluded from the analysis of both QTc and R-R intervals. For patients with preexcitation, measurements were performed with use of the JT interval, the RT interval, or the earliest notch in the QRS complex at the discretion of the core laboratory cardiologist. The RT and JT measurements were then transformed into QT measurements by addition of the duration of the non-preexcited QR or QRS complex to the measured value. For tracings in which the first notch in the QRS complex was used, no further correction was made. Tracings that showed marked axis shifts because of a change in preexcitation pattern were excluded from QT analysis. Patients with a stable, not intermittent, intraventricular conduction delay were used for analysis; the reported QT duration was corrected to reflect normal QRS duration for age rather than the actual measured QRS complex. Other reasons for excluding QT interval from the analysis were flat $\mathrm{T}$ wave and motion artifact.

The electrocardiographic tracings were placed on a digitizing pad (SummaSketch III; Summagraphics, Seymour, Conn). The end of the $\mathrm{T}$ wave was determined by manual drawing of a tangent to the steepest portion of the down-sloping $\mathrm{T}$ wave. The point at which the tangent intersected the isoelectric line was used to designate the end of the $T$ wave.

Plots of QTc or R-R intervals against time were used to exclude a possible time-dependent variation of the QTc or R-R intervals during the baseline session. Plots of the baseline QTcB or QTcF values against the R-R intervals were used to test the adequacy of the Bazett or Fridericia formula for correcting the QT intervals for heart rate.

The impact of congestive heart failure (NYHA Class I or II) and digoxin coadministration on the pharmacokinetics or pharmacodynamics of sotalol was evaluated by exploratory methods. Digoxin was the only drug that was chronically coadministered to 3 patients.

Statistics. Mean values, standard deviations, and coefficients of variation for the pharmacokinetic and pharmacodynamic parameters were calculated. Linear regression analyses were performed for evaluation of the relationship between $\mathrm{Cl} / \mathrm{F}$ and $\mathrm{BSA}$ or $\mathrm{CL}_{\mathrm{CR}}$. The generalized Estimating Equation Model was used to explore the relationship between pharmacologic effect and dose or concentration of sotalol. A normal probability distribution was used in the model with the use of the pharmacokinetic parameters as covariates and the dose or drug concentration level as a class variable. The multivariate analysis of variance model was used 
Table I. Demographics of pediatric patients

\begin{tabular}{|c|c|c|c|c|c|c|c|c|c|c|}
\hline Patient No. & Age & Sex & Race & $\begin{array}{l}H T \\
(\mathrm{~cm})\end{array}$ & $\begin{array}{l}B W \\
(k g)\end{array}$ & $\begin{array}{l}B S A \\
\left(m^{2}\right)\end{array}$ & $\begin{array}{c}C L_{C R} \\
(\mathrm{~mL} / \mathrm{min} / \\
\left.1.73 \mathrm{~m}^{2}\right)\end{array}$ & $\begin{array}{l}\text { Type of } \\
\text { arrhythmia }\end{array}$ & $\mathrm{CHF}$ & $\begin{array}{c}\text { Digoxin } \\
\text { comedication }\end{array}$ \\
\hline \multicolumn{11}{|c|}{ Neonates $30 \mathrm{~d}$ and younger } \\
\hline 1 & 4 & Female & White & 46.0 & 2.2 & 0.17 & 21.7 & SVT & + & \\
\hline 2 & 11 & Male & White & 50.0 & 3.2 & 0.21 & 37.5 & SVT/VT & & \\
\hline 3 & 19 & Female & White & 53.5 & 3.7 & 0.23 & 80.3 & SVT* $^{*}$ & & \\
\hline 4 & 21 & Male & White & 54.0 & 3.6 & 0.23 & 81.0 & SVT & + & + \\
\hline 5 & 27 & Male & Black & 52.5 & 4.2 & 0.25 & 59.1 & $\mathrm{SVT} \dagger$ & & \\
\hline 6 & 28 & Female & White & 55.0 & 4.3 & 0.26 & 41.3 & $\mathrm{SVT}^{*}$ & + & \\
\hline 7 & 30 & Female & White & 51.0 & 4.0 & 0.22 & 38.3 & SVT $^{*}$ & & \\
\hline \multicolumn{11}{|c|}{ Infants between 1 and $24 \mathrm{mo}$} \\
\hline 8 & 2.3 & Male & White & 59.0 & 5.0 & 0.29 & 132.8 & $\mathrm{SVT}^{*}$ & & \\
\hline 9 & 2.8 & Female & White & 60.0 & 4.9 & 0.29 & 90.0 & SVT & + & \\
\hline 10 & 3.0 & Male & Black & 65.5 & 9.0 & 0.40 & 98.3 & SVT* & & \\
\hline 11 & 3.7 & Male & White & 64.0 & 7.7 & 0.37 & 96.0 & SVT* & & \\
\hline 12 & 5.2 & Female & White & 64.0 & 5.5 & 0.31 & 96.0 & SVT & & \\
\hline 13 & 13.5 & Male & Black & 81.0 & 12.0 & 0.52 & 91.1 & SVT* & & \\
\hline 14 & 15.5 & Male & White & 80.0 & 12.0 & 0.52 & 90.0 & $\mathrm{VT} \ddagger$ & & \\
\hline 15 & 16.0 & Female & White & 76.0 & 9.9 & 0.44 & 114.0 & SVT & & + \\
\hline 16 & 22.3 & Male & White & 87.0 & 13.0 & 0.54 & 97.9 & SVT* & & \\
\hline \multicolumn{11}{|c|}{ Children between 2 and $12 y$} \\
\hline 17 & 2.6 & Male & White & 92.5 & 15.1 & 0.62 & 127.2 & SVT* & & \\
\hline 18 & 5.8 & Female & Hispanic & 106.5 & 16.4 & 0.70 & 83.7 & SVT & & + \\
\hline 19 & 5.8 & Male & White & 111.6 & 19.7 & 0.78 & 153.5 & SVT & & \\
\hline 20 & 7.3 & Female & White & 113.0 & 23.5 & 0.86 & 124.3 & SVT & & \\
\hline 21 & 7.6 & Male & Other & 127.0 & 31.6 & 1.06 & 116.4 & $\mathrm{SVT} \dagger$ & & \\
\hline 22 & 9.7 & Male & White & 138.5 & 34.6 & 1.15 & 127.0 & SVT & & \\
\hline 23 & 10.7 & Female & White & 154.2 & 37.1 & 1.26 & 169.6 & SVT & & \\
\hline 24 & 11.8 & Female & White & 138.0 & 38.0 & 1.20 & 126.5 & SVT & & \\
\hline 25 & 12.2 & Female & White & 164.0 & 50.2 & 1.51 & 112.8 & SVT & & \\
\hline
\end{tabular}

HT, Height; BW, body weight; CHF, mild congestive heart failure (NYHA Class I or II). *Wolff-Parkinson-White syndrome.

$\dagger$ Not included in analysis of QT and R-R intervals.

$\ddagger$ Not included in analysis of R-R interval.

to estimate correlation coefficients. The model included repeated measures with the following factors: patients and dose level. For comparisons of pharmacologic effect or pharmacokinetic parameters between patients with BSAs of more than $0.33 \mathrm{~m}^{2}$ and those with BSAs of less than $0.33 \mathrm{~m}^{2}$, we used the mixed model with the dose level as covariate. The sample size of the targeted neonatal or infant population with SVT or VT was based on clinical and logistic rather than statistical considerations.

\section{RESULTS}

The results are reported as mean values ( \pm standard deviations) unless stated otherwise. Twenty-one study sites participated. Twenty-five patients were enrolled in the study (Table I). The age range of the patients was 7 days to 12.2 years. Thirteen patients were male and 12 were female. Twenty patients were white, 3 were black, 1 was Hispanic, and 1 was of other ethinic origin. All of the patients had age-related normal $\mathrm{CL}_{\mathrm{CR}}$ values that ranged from 22 to $170 \mathrm{~mL} / \mathrm{min} / 1.73 \mathrm{~m}^{2}$. Twenty-three of the patients had SVT, 1 patient had VT, and 1 patient had both SVT and VT. Of 9 patients diagnosed with Wolff-Parkinson-White syndrome, 7 had preexcitation. Four patients were diagnosed with mild congestive heart failure (NYHA Class I or II), which was attributed to SVT before screening. Left ventricular dysfunction was diagnosed in utero by echocardiography in 1 patient; it resolved at birth. Three patients received a continuous regimen of digoxin. One of these patients was also diagnosed with mild congestive heart failure (NYHA Class I or II). In addition to digoxin, a variety of drugs were coadministered to some of the patients during the study.

Pharmacokinetics. Pharmacokinetic data were available for all 25 patients. However, not all pharmacoki- 


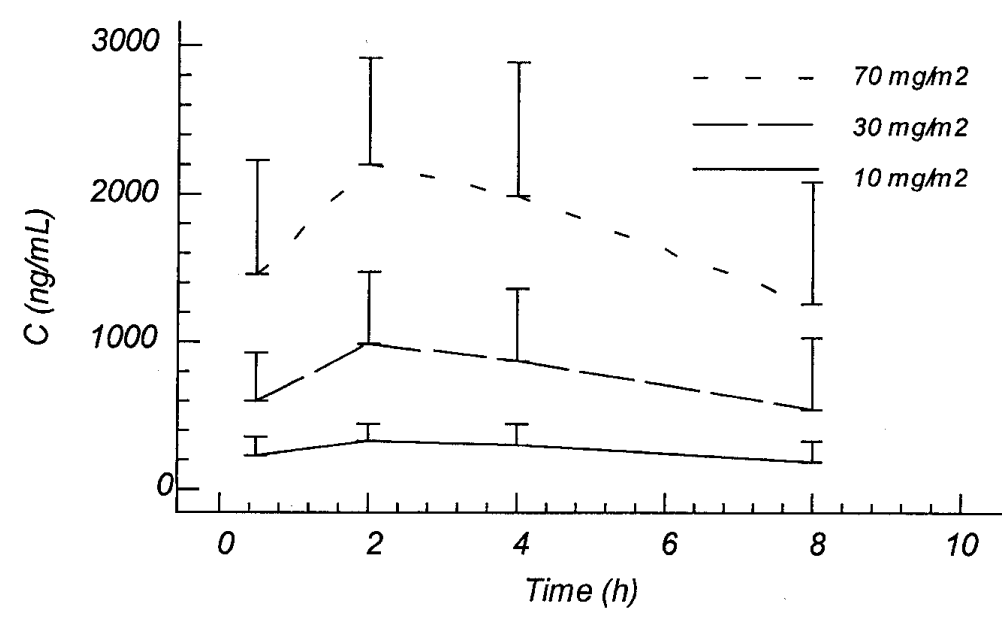

Fig 1. Linear plot of the mean and standard deviation of sotalol plasma concentration observed at the 3 dose levels in the 3 age groups: neonates, infants, and children older than 2 to 12 years.

Table II. Pharmacokinetic parameters of sotalol in the pediatric patients

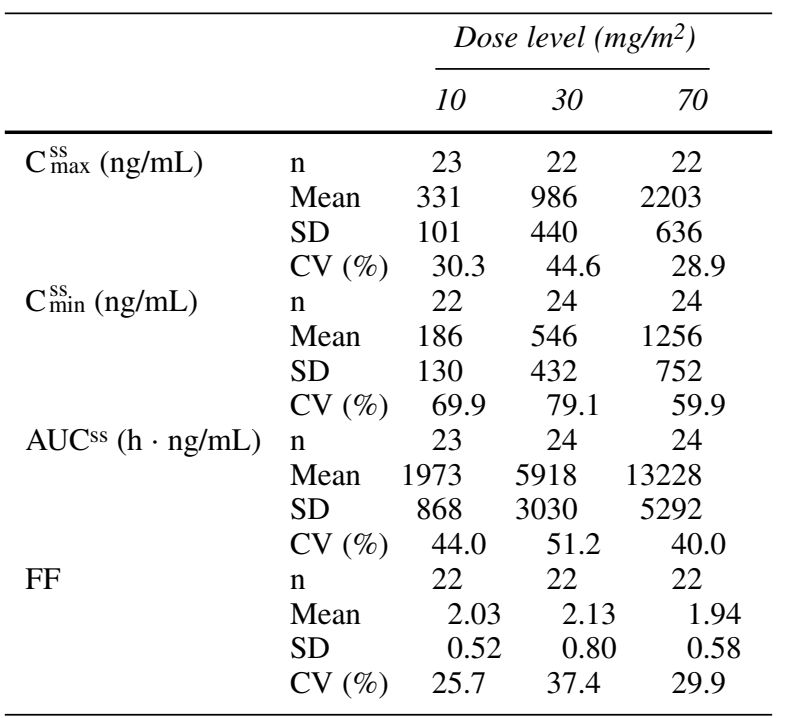

$\mathrm{SD}$, Standard deviation; $\mathrm{CV}$, coefficient of variation; $\mathrm{C}$ min, nominal trough sotalol plasma concentration at steady state measured 8 hours postdose in the third, sixth, or ninth dose interval; FF, fluctuation factor computed as the ratio of $C_{\max }^{\text {ss }}$ to $C_{\min }^{\text {ss }}$.

netic parameters could be calculated for all 25 patients at each of the 3 dose levels. The drug concentrations increased with dose (Fig 1 and Table II). The AUC ${ }^{\text {ss }}$ values increased by factors of 3.00 and 6.70 when the dose was increased by factors of 3.00 and 7.00 , respectively. The corresponding increases of the $\mathrm{C}_{\max }^{\mathrm{ss}}$ values were 2.98 and 6.65 , respectively. The fluctuation factors obtained at the 10,30 , and $70 \mathrm{mg} / \mathrm{m}^{2}$ dose levels for the entire population were $2.03 \pm 0.52,2.13 \pm 0.80$, and $1.94 \pm 0.58$, respectively (Table II). Taken together, these results indicated that the pharmacokinetics of sotalol in this pediatric population were dose proportionate.

Significant linear relationships existed between $\mathrm{Cl} / \mathrm{F}$ and BSA or $\mathrm{CL}_{\mathrm{CR}}(P<.001$; Figs 2 and 3$)$. The smallest children (BSA $<0.33 \mathrm{~m}^{2}$ ) displayed an importantly larger drug exposure (AUCss and $\mathrm{C}_{\text {max }}^{\text {ss }}$ ) than those with a BSA larger than $0.33 \mathrm{~m}^{2}$ (Table III), with the BSAnormalized doses. An examination of the individual data of the smallest patients did not indicate any deviation from dose-proportionate linear pharmacokinetics for sotalol.

Pharmacodynamics. QTe and R-R interval data were analyzable for 23 and 22 patients, respectively. However, not all of the pharmacodynamic parameters for the QTc and R-R intervals could be calculated at each of the 3 dose levels for the 23 and 22 patients, respectively, with analyzable data. The plot of the pooled QTcB or QTcF interval against the corresponding R-R intervals at baseline showed that only the correction procedure according to Bazett resulted in an independence of the QTc intervals from the heart rate (Fig 4). Consequently, we will discuss only the results obtained with the QTcB intervals. There was no evidence for a systematic time dependency of the QTcB or R-R intervals observed during the baseline session. The baseline R-R intervals, but not the corresponding QTcB intervals, were dependent on BSA (Table IV).

The percentage of change in $E_{\max }^{\mathrm{sS}}, \mathrm{E}_{\mathrm{min}}^{\mathrm{sS}}$, and $A U E^{s s}$ values for the QTcB and R-R intervals showed a dosedependent increase (Table V). The effect of sotalol on the R-R interval was greater than that on the QTcB 


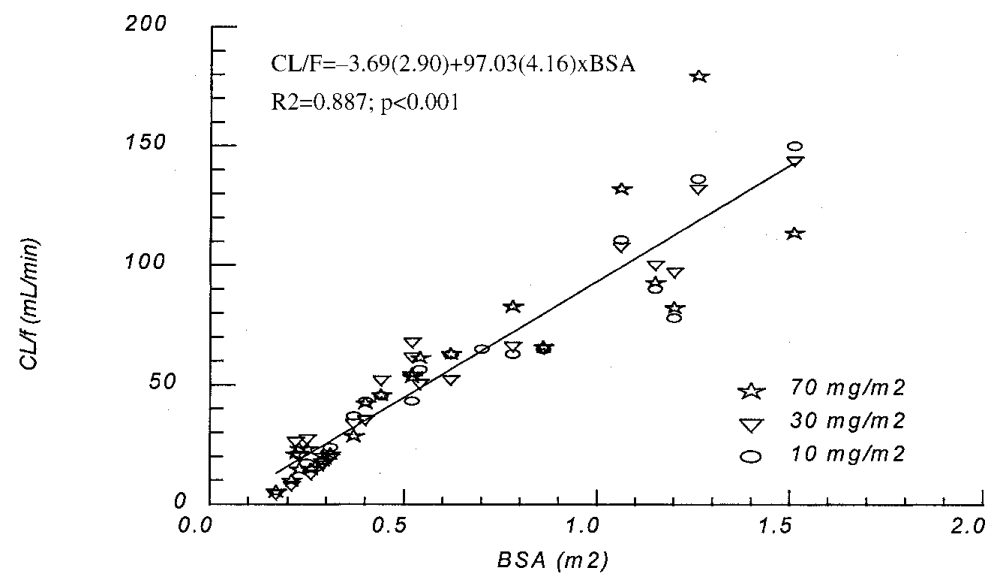

Fig 2. Plot of the $\mathrm{Cl} / \mathrm{F}$ of sotalol against the BSA at dose levels of 10,30 , and $70 \mathrm{mg} / \mathrm{m}^{2}$ of sotalol.

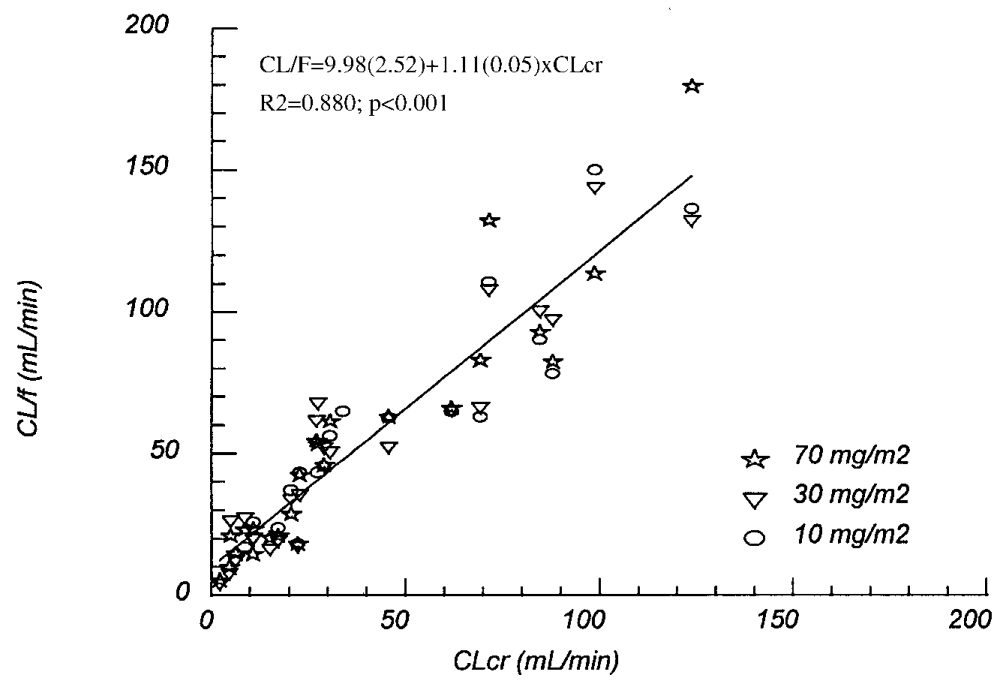

Fig 3. Plot of the $\mathrm{Cl} / \mathrm{F}$ of sotalol against $\mathrm{CL}_{\mathrm{CR}}$ at dose levels of 10,30 , and $70 \mathrm{mg} / \mathrm{m}^{2}$ of sotalol.

Table III. Mean pharmacokinetic and pharmacodynamic parameters of sotalol and BSA in small and large children

\begin{tabular}{|c|c|c|c|c|c|c|c|c|c|c|c|}
\hline \multirow[b]{2}{*}{$B S A\left(m^{2}\right)$} & \multirow{2}{*}{$\begin{array}{c}\text { Dose } \\
\left(m g / m^{2}\right)\end{array}$} & \multicolumn{2}{|r|}{$A U C^{s s}$} & \multirow{2}{*}{$\begin{array}{c}\text { IFAUC } C^{s s} \\
(\%)\end{array}$} & \multicolumn{2}{|r|}{$C \max$} & \multirow{2}{*}{$\begin{array}{c}I F C_{\max }^{s s} \\
(\%)\end{array}$} & \multicolumn{4}{|c|}{$\% \triangle A U E^{s s}$} \\
\hline & & $n$ & $h \cdot n g / m L$ & & $n$ & $n g / m L$ & & $n$ & $Q T c$ & $n$ & $R-R$ \\
\hline \multirow[t]{3}{*}{$<0.33$} & 10 & 9 & $2529 \pm 1175$ & 56.5 & 9 & $401 \pm 111$ & 40.3 & 6 & $5 \pm 6$ & 8 & $7 \pm 9$ \\
\hline & 30 & 10 & $7708 \pm 4079$ & 66.1 & 9 & $1219 \pm 584$ & 43.3 & 8 & $6 \pm 6$ & 9 & $11 \pm 12$ \\
\hline & 70 & 10 & $16,581 \pm 6509$ & 53.1 & 10 & $2553 \pm 615$ & 28.9 & 6 & $10 \pm 4$ & 9 & $14 \pm 15$ \\
\hline \multirow[t]{3}{*}{$\geq 0.33$} & 10 & 14 & $1616 \pm 274$ & & 14 & $286 \pm 63$ & & 14 & $0 \pm 3$ & 12 & $2 \pm 8$ \\
\hline & 30 & 14 & $4640 \pm 706$ & & 13 & $851 \pm 185$ & & 13 & $2 \pm 3$ & 11 & $7 \pm 9$ \\
\hline & 70 & 14 & $10,833 \pm 2324$ & & 12 & $1981 \pm 507$ & & 13 & $5 \pm 4$ & 11 & $11 \pm 12$ \\
\hline$P$ value* & & & .0021 & & & .0021 & & & .0043 & & .064 \\
\hline
\end{tabular}

IFAUCss, Increase factor of AUCss in small children compared with large children; IFC ${ }_{\text {max }}^{\text {ss }}$ increase factor of $\mathrm{C}_{\text {max }}^{\text {ss }}$ in small children compared with large children; $\% \Delta \mathrm{AUE}^{\mathrm{ss}}$, percentage of increase in area under the QTcB or R-R effect time curve at steady-state, represents average percentage of prolongation of QTcB or R-R interval during a dose interval.

*The $P$ value was calculated from mixed model with the use of dose level as a covariate. 

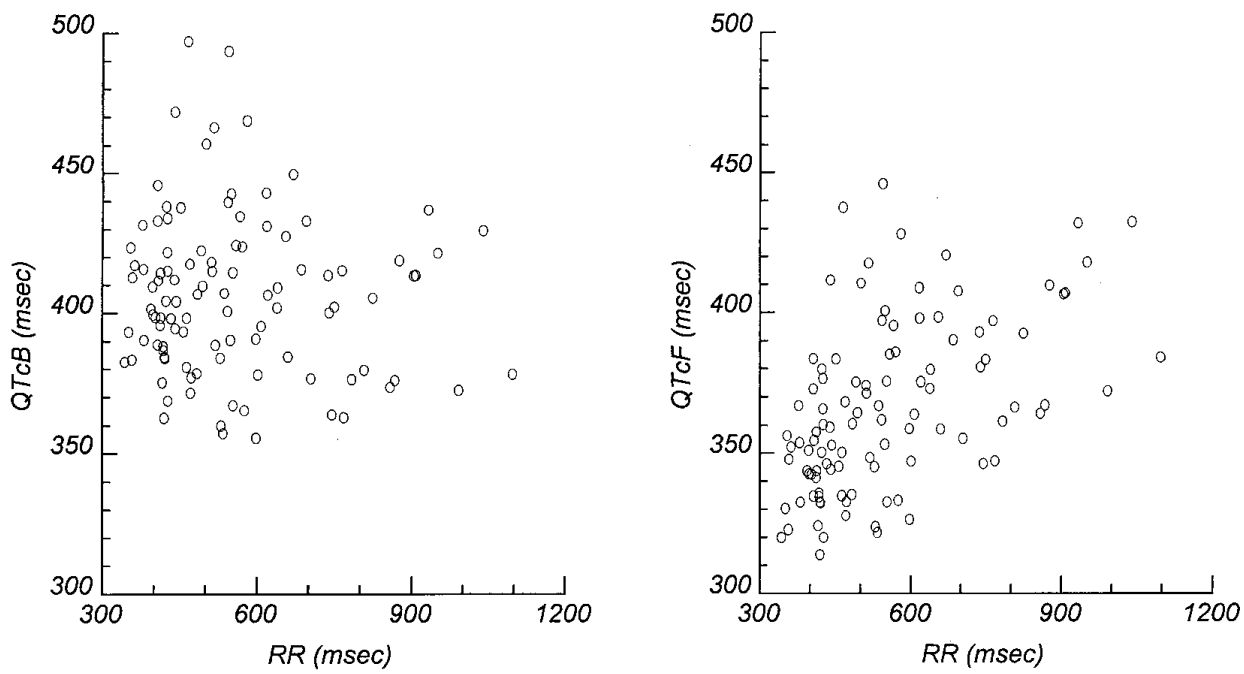

Fig 4. Scatter plot of the $\mathrm{QTcB}$ and $\mathrm{QTcF}$ intervals against the R-R intervals at baseline.

Table IV. Mean baseline values of the QTc and R-R intervals by BSA

\begin{tabular}{llrr}
\hline & & \multicolumn{2}{c}{$B S A\left(m^{2}\right)$} \\
\cline { 3 - 4 } Parameter & & $<0.33$ & $\geq 0.33$ \\
\hline Eave $_{\text {baTcB; ms) }}^{\mathrm{b}}$ & $\mathrm{n}$ & 8 & 14 \\
& Mean & 405 & 405 \\
& SD & 17 & 25 \\
Eave $^{b}(\mathrm{R}-\mathrm{R} ; \mathrm{ms})$ & $\mathrm{n}$ & 9 & 12 \\
& Mean & 440 & 620 \\
& SD & 47 & 162 \\
\hline
\end{tabular}

SD, Standard deviation.

interval. The $\mathrm{tE}_{\text {max }}^{\mathrm{SS}}$ values occurred between 2.9 and 3.7 hours for the QTcB interval and between 2.2 and 3.3 hours for the R-R interval after the administration of sotalol at the 3 dose levels tested. The respective percentage of change in AUEss values that reflected the average effect during a dose interval suggested that a notable and lasting Class III effect was achieved at the highest dose level of $70 \mathrm{mg} / \mathrm{m}^{2}$. In contrast, a meaningful and durable $\beta$-blocking effect was already achieved at the $30 \mathrm{mg} / \mathrm{m}^{2}$ level for all groups and even at the lowest dose level of $10 \mathrm{mg} / \mathrm{m}^{2}$ for the smallest children (BSA $<0.33 \mathrm{~m}^{2}$; Table III).

When the effect data on the QTcB interval obtained at the 3 dose levels were pooled, the respective values for $\mathrm{E}_{\max }^{\mathrm{SS}}$ and $\mathrm{E}_{\min }^{\mathrm{SS}}$ (or the respective baseline corrected parameters) were significantly related to the dose lev-
Table V. Mean pharmacodynamic parameters of sotalol in the pediatric patients

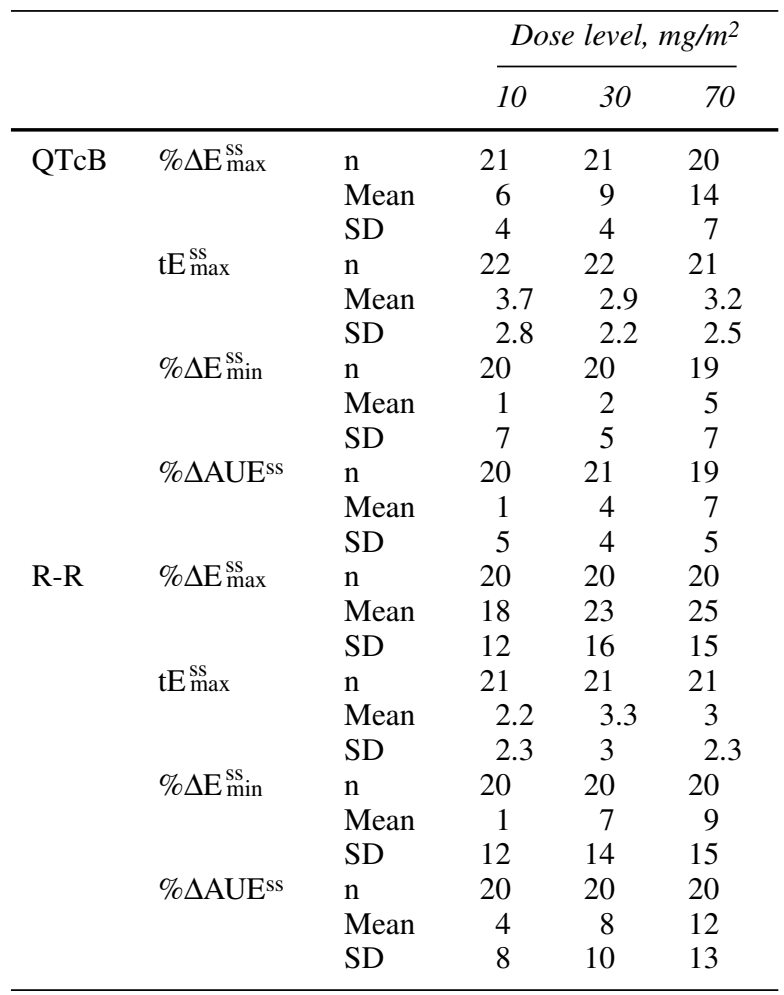

$\% \Delta \mathrm{E}_{\max }^{\mathrm{ss}}$, Percentage of increase of observed maximum $\mathrm{QTcB}$ or R-R interval at steady-state; SD, standard deviation; $\% \Delta \mathrm{E}_{\mathrm{min}}^{\mathrm{ss}}$, percentage of increase of nominal minimum QTcB or R-R interval at steady-state; $\% \Delta \mathrm{AUE}$ ss, percentage of increase of area under the QTcB or R-R effect time curve at steadystate, represents average percent prolongation of QTc or R-R interval during a dose interval. 


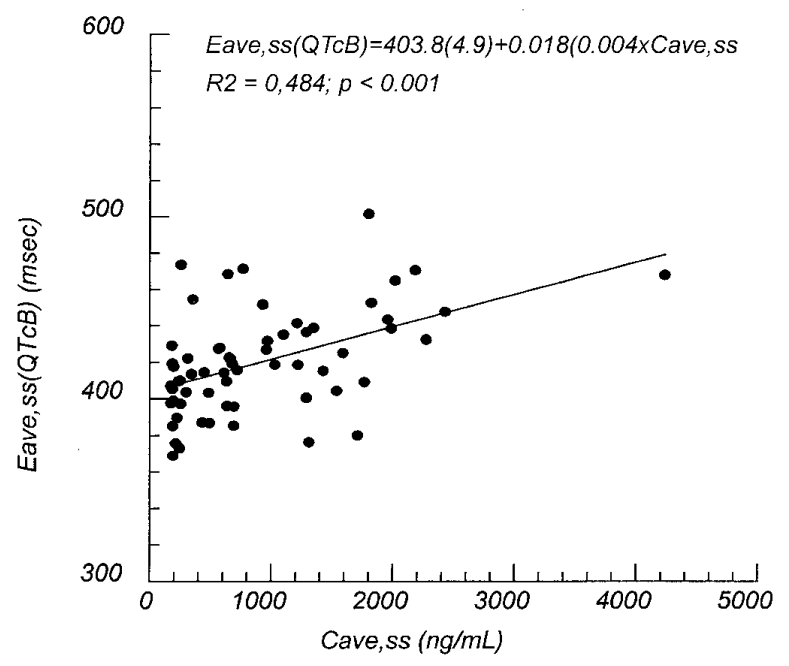

Fig 5. Linear plot of the pooled average QTcB interval ( $\left.\mathrm{E}_{\mathrm{ave}}^{\mathrm{Ss}}\right)$ against the average sotalol plasma concentration $\left(\mathrm{C}_{\text {ave }}^{\text {ss }}\right)$ at steady state.

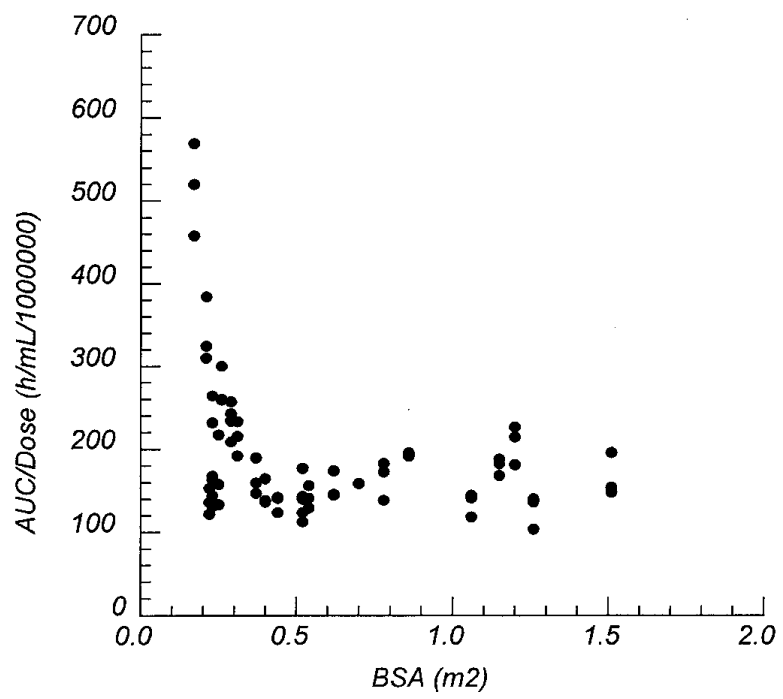

Fig 6. Plot of the dose-normalized AUC ${ }^{\text {ss }}$ against BSA in the pediatric patients.

els $(P<.001)$. For the R-R interval, only the $\mathrm{E}_{\max }^{\mathrm{ss}}$ values were significantly related to the dose $(P=.0205)$. There was significant interpatient variation in the Class III activity, with a few nonresponders among a majority of responders at the $70 \mathrm{mg} / \mathrm{m}^{2}$ dose level.

Pharmacokinetics and pharmacodynamics. When the effect data on the QTcB interval obtained at the 3 dose levels were pooled, there was a significant relationship between $\mathrm{E}_{\mathrm{ave}}^{\mathrm{ss}}$ (or the baseline corrected parameters) and $\mathrm{C}_{\text {ave }}^{\text {ss }}(P<.001 ;$ Fig 5$)$. In contrast to the QTcB inter- val, no such relationship with the drug concentration was apparent for the effect on the R-R interval.

Examination of subpopulations. The drug exposure parameters, AUCss and $\mathrm{C}_{\max }^{\mathrm{ss}}$, were significantly greater in patients with BSAs of less than $0.33 \mathrm{~m}^{2}$ than in the larger children (Table III). The overall mean increases in $\mathrm{AUC}^{\mathrm{ss}}$ and $\mathrm{C}_{\mathrm{max}}^{\mathrm{ss}}$ were $58.6 \%$ and $37.5 \%$, respectively, in the smallest children. In contrast to the smallest children, drug exposure among the larger children was similar to the applied dose regimen (Fig 6). BSA with $\mathrm{CL}_{\mathrm{CR}}$ 
Table VI. Proportion (percentage) of pediatric patients with QTcB of $\geq 525 \mathrm{~ms}$ or increase in QTc above baseline $>60 \mathrm{~ms}^{*}$ by BSA and dose level

\begin{tabular}{|c|c|c|c|c|}
\hline \multirow[b]{2}{*}{ Dose level $\left(\mathrm{mg} / \mathrm{m}^{2}\right)$} & \multicolumn{2}{|c|}{$Q T c B \geq 525 \mathrm{~ms}$} & \multicolumn{2}{|c|}{$\Delta Q T c B>60 \mathrm{~ms}$} \\
\hline & All & $B S A \leq 0.33$ & All & $B S A \leq 0.33$ \\
\hline 10 & 0 & 0 & $1 / 21(4.8 \%)$ & $1 / 9(11.1 \%)$ \\
\hline 30 & 0 & 0 & $2 / 21(9.5 \%)$ & $2 / 9(22.2 \%)$ \\
\hline 70 & $2 / 21(9.5 \%)$ & $1 / 9(11.1 \%)$ & $10 / 21(47.6 \%)$ & $5 / 9(55.5 \%)$ \\
\hline
\end{tabular}

*More than $15 \%$ increase.

was shown to be the most important predictor for $\mathrm{Cl} / \mathrm{F}$. BSA is more discerning than age, and therefore BSA is a more appropriate criterion for a subpopulation analysis.

In agreement with the pharmacokinetic data, the pharmacodynamic results also showed larger percentage of change in AUEss values for the QTcB and R-R intervals in the smallest patients (BSA $<0.33 \mathrm{~m}^{2}$; Table III). The QTcB values were significantly greater than those in the larger children $(P=.0043)$. As a consequence, relevant and durable Class III effects were apparent in the smallest children already at the 30 and $10 \mathrm{mg} / \mathrm{m}^{2}$ dose levels, respectively. There was also a larger proportion of the smallest children with $\Delta \mathrm{QTcB}$ values of more than $60 \mathrm{~ms}$ at all 3 dose levels compared with the entire pediatric population tested (Table VI). QTc values of more than $525 \mathrm{~ms}$ were observed in only 2 subjects, a small child with a BSA of less than 0.33 $\mathrm{m}^{2}$ and a larger child with a BSA of $0.33 \mathrm{~m}^{2}$ or more.

Interactions with disease and other drugs. There was no overt indication that mild congestive heart failure (NYHA Class I or II) had an important impact on the pharmacokinetics or pharmacodynamics of sotalol. There also appeared to be no strong evidence for an important interaction of digoxin with the pharmacokinetics or pharmacodynamics of sotalol. It is unlikely that SVT or VT had an impact on the pharmacokinetics of sotalol. However, it is possible that the tachyarrhythmias increased the interpatient variation of the Class III or $\beta$-blocking activities of sotalol.

Safety. No deaths or serious drug-related AEs were reported. One patient who received the $10 \mathrm{mg} / \mathrm{m}^{2}$ dose was dropped from the study because of an increased frequency of sinus pauses. The patient had a history of sinus pauses and surgical correction for congenital heart disease (Tetralogy of Fallot). Other cardiovascular AEs were seen at the 30 and $70 \mathrm{mg} / \mathrm{m}^{2}$ dose levels in 7 patients: 3 patients (2 infants with a BSA $<0.33 \mathrm{~m}^{2}$ and 1 child who was 11.8 years old) experienced QTc or QT prolongations, 1 patient (a 3-week-old neonate) had an abnormal ECG with left axis deviation, 1 patient (a 5.8-year-old child) had sinus bradycardia, 1 patient (a 10.7-year-old child) showed an increased severity of atrial flutter and reported chest pain, and 1 patient (a 5.8-year-old child) experienced vasodilatation. Except for the vasodilatation, the AEs were rated to be at least possibly related to sotalol.

\section{DISCUSSION}

The adjusted dose regimen applied in this study resulted in fluctuation factors close to 2.0; this is a desirable feature considering the relatively narrow therapeutic range of sotalol in adults with the target disease. The dose adjustment based on BSA applied in this study led to similar AUCss and $\mathrm{C}_{\max }^{\mathrm{ss}}$ values in all but the smallest pediatric patients. In the smallest children (BSA $<0.33 \mathrm{~m}^{2}$ ), an important increase in drug exposure was observed with the use of the empirically adjusted doses. These results were also in agreement with the findings obtained in the smallest children in a single-dose pharmacokinetic study that was conducted with neonates, infants, preschool children, and school children. ${ }^{9}$ In a population pharmacokinetic analysis of the combined databases from this study and the pharmacokinetic study, ${ }^{9}$ BSA was found to be the most important covariate. ${ }^{15}$

It is important to note that smaller clearance values have been reported in neonates for other drugs that, similar to sotalol, are mainly excreted unchanged by the kidney in adults. ${ }^{16,17}$ The values of $\mathrm{CL}_{\mathrm{CR}}$ normalized for a BSA of $1.73 \mathrm{~m}^{2}$ in the smallest children $(65$ $\mathrm{mL} / \mathrm{min} / 1.73 \mathrm{~m}^{2} \pm 35 \mathrm{~mL} / \mathrm{min} / 1.73 \mathrm{~m}^{2}$ ) were clearly lower than those in the larger children (127 $\mathrm{mL} / \mathrm{min} / 1.73 \mathrm{~m}^{2} \pm 24 \mathrm{~mL} / \mathrm{min} / 1.73 \mathrm{~m}^{2}$ ); this suggests a reduced excretory function relative to body size in the smallest children.

Studies of children of different ages have shown that the ratio of renal to oral total clearance of digoxin, a drug similar to sotalol that is mainly excreted unchanged by the kidney, does not significantly change during the pediatric developmental and body size changes. ${ }^{16}$ Therefore it can be assumed that in children, 
as in adults, sotalol is mainly eliminated by the kidney. The observed close dependence of $\mathrm{Cl} / \mathrm{F}$ on $\mathrm{CL}_{\mathrm{CR}}$ supports this assumption (Fig 3).

Congestive heart failure can have an impact on the pharmacokinetics and pharmacodynamics of drugs. ${ }^{18,19}$ However, adults in whom alterations of the pharmacokinetics of drugs have been reported were generally in more advanced stages of the disease (NYHA Class IIIV) ${ }^{20-25}$ than the patients in this study (NYHA Class I or II). In this study, no gross deviations of the pharmacokinetics and pharmacodynamics of sotalol in the children with mild congestive heart failure were observed. Also, it is unlikely that an important disease-sotalol interaction took place. However, a firm conclusion cannot be drawn on the basis of the limited database available.

In the absence of a control group, the possible impact of SVT or VT on the pharmacokinetics or pharmacodynamics of sotalol could not be investigated in this study. Although the type of tachyarrhythmias in this study probably did not modify the disposition or the effects of sotalol significantly, it is possible that SVT or VT contributed to the observed relevant interpatient variation of the Class III and $\beta$-blocking effects of sotalol. 26

In adults, digoxin is eliminated by the same routes, in the same proportion, and possibly by the same mechanisms as sotalol. ${ }^{27}$ Digoxin is known to reduce the heart rate and to shorten the QTc interval. ${ }^{28,29}$ Therefore digoxin could theoretically interact with sotalol. However, the results obtained from this study do not support the notion of an important digoxin-sotalol interaction. Clearly, the database is too limited for a definitive conclusion.

In the entire pediatric population studied, a notable and lasting $\beta$-blocking effect was found, starting at the $30 \mathrm{mg} / \mathrm{m}^{2}$ dose level, whereas a corresponding Class III effect was only observed at the highest dose level of $70 \mathrm{mg} / \mathrm{m}^{2}$. However, consistent with the increased plasma concentration, the smallest children (BSA $<0.33$ $\mathrm{m}^{2}$ ) had pharmacologically important $\beta$-blocking effects at even the lowest dose level of $10 \mathrm{mg} / \mathrm{m}^{2}$. These findings were in accordance with reports of adult subjects and patients that have indicated that sotalol elicits a $\beta$-blocking effect at lower doses than the Class III effect. $^{30,31}$ It should be noted that in the previous reports of adults the $\beta$-blocking effect on the R-R interval or heart rate was not measured at rest but was measured after induction of tachycardia by either isoproterenol infusion or exercise. ${ }^{30,31}$

Compared with the pharmacokinetic results, the dependency of the Class III and $\beta$-blocking effects on the BSA was less certain. The observed increase in drug exposure, the tendency for more pronounced effects in the smallest children (BSA $<0.33 \mathrm{~m}^{2}$ ), and the important interpatient variation observed in the entire pediatric population mandate sotalol dose regimens that are guided by QTc interval and heart rate monitoring.

The observed statistically significant relationships between response and drug concentration for the QTcB interval in the pediatric population were in accordance with similar findings in adult subjects. ${ }^{30-34}$ The absence of a definable relationship between response and drug concentration for the R-R interval in the pediatric population may have to do with the possible impact of age or BSA on this relationship. Also, the R-R intervals were measured during resting conditions in the children, whereas the existence of a relationship between drug concentration and $\beta$-blocking effect of sotalol in adults was found with the use of exercise- or isoproterenol-induced tachycardia conditions. ${ }^{30,31}$

\section{CONCLUSIONS}

The main findings in the 4 pediatric age groups (neonates, infants, children older than 2 years to 7 years, and children older than 7 years to 12 years) receiving multiple doses of 10,30 , and $70 \mathrm{mg} / \mathrm{m}^{2}$ of sotalol with the use of an extemporaneous formulation were as follows. (1) The applied dosage regimen with 8-hour intervals for sotalol achieved ideally small fluctuation factor values of $\approx 2.0$ between nominal peak and trough steadystate concentrations. (2) The pharmacokinetics of sotalol in the pediatric population were first order and dose proportionate. (3) There were statistically significant correlations between $\mathrm{Cl} / \mathrm{F}$ and $\mathrm{BSA}$ or $\mathrm{CL}_{\mathrm{CR}}$. (4) The $\mathrm{AUC}$ ss and $\mathrm{C}_{\max }^{\mathrm{ss}}$ values were similar in patients with $\mathrm{BSA}$ of more than $0.33 \mathrm{~m}^{2}$, but in children with smaller BSA values, a significantly greater exposure to the drug was observed with the BSA-normalized dosages.

Notable and lasting Class III effects of sotalol were observed in the pediatric population at the highest dose level of $70 \mathrm{mg} / \mathrm{m}^{2}$. Important and durable $\beta$-blocking effects were found at the 30 and $70 \mathrm{mg} / \mathrm{m}^{2}$ dose levels. Both effects showed important intersubject variation, which indicated important differences in the responsiveness of the individual pediatric patients. The Class III and $\beta$-blocking effects tended to be more pronounced in the smallest children (BSA $<0.33 \mathrm{~m}^{2}$ ). Statistically significant dose level dependencies existed for the Class III and $\beta$-blocking effects of sotalol in the pediatric population. Finally, there were statistically significant linear correlations between drug concentration and pharmacologic activity on the QTcB interval. No such correlation could be shown for the $\beta$-blocking effect measured at rest in the children. 


\begin{abstract}
Members of the Pediatric Sotalol Investigators include Dr Dianne Atkins, University of Iowa, Iowa City; Dr David Chan, Columbus Children's Hospital, Columbus, Ohio; Dr MacDonald Dick, University of Michigan, Ann Arbor; Dr Michael R. Epstein, Children's Hospital, Medical Center, Cincinnati; Dr Christopher Erickson, Arkansas Children's Hospital, Little Rock; Dr Frank A. Fish, Vanderbilt University, Nashville, Tenn; Dr Steven Fishberger, St Joseph's Children Hospital, Paterson, NJ, and Clinical Research Center, Mount Sinai School of Medicine, New York; Dr Richard Friedman, Texas Children's Hospital, Houston; Dr J. Edward Hulse, Children's Mercy Hospital, Kansas City, Mo; Dr Ronald J. Kanter, Duke University Medical Center, Durham, NC; Dr Peter Karpawich, Children's Hospital of Michigan, Detroit; Dr Robert Pass, Babies Hospital 2 N, Columbia Presbyterian Medical Center, New York; Dr William Scott, Children's Medical Center of Dallas, Texas; Dr Margret Strieper, The Children's Heart Center, Atlanta, Ga; Dr Ronn Tanel, Children's Hospital of Philadelphia, Penn; Dr John Triedman, Boston Children's Hospital, Mass; Dr George F. Van Hare, UCSF School of Medicine, Palo Alto, Calif; and Dr Frank Zimmerman, St Louis Children Hospital, Mo.
\end{abstract}

\section{References}

1. The current labeling for Betapace ${ }^{\circledR}$ (sotalol $\mathrm{HCl}$ ). In: Physicians' desk reference. 55th ed. Montvale (NJ): Medical Economics; 2001. p. 905-8.

2. Maragnes P, Tipple M, Fournier A. Effectiveness of oral sotalol treatment of pediatric arrhythmia. Am J Cardiol 1992;69:751-4.

3. Pfammatter JP, Paul T, Lehmann C, Kallfelz HC. Efficacy and proarrhythmia of oral sotalol in pediatric patients. $\mathrm{J}$ Am Coll Cardiol 1995;26:1002-7.

4. Tanel RE, Walsh EP, Lulu JA, Saul JP. Sotalol for refractory arrhythmias in pediatric and young adult patients: initial efficacy and long-term outcome. Am Heart J 1995;130:791-7.

5. Beaufort-Krol GCM, Brink-Boelkens MTE. Effectiveness of sotalol for atrial flutter in children after surgery for congenital heart disease. Am J Cardiol 1997;79:92-4.

6. The current labeling for Betapace $\mathrm{AF}^{\mathrm{TM}}$ (sotalol $\mathrm{HCl}$ ). In: Physicians' desk reference. 55th ed. Montvale (NJ): Medical Economics; 2001. p. 908-12.

7. Antilla M, Arstila M, Pfeffer M, Tikkanen R, Valinkoski V, Sundqvist H. Human pharmacokinetics of sotalol. Acta Pharmacol Toxicol (Copenh) 1976;39:118-28.

8. Hanyok JJ. Clinical pharmacokinetics of sotalol. Am J Cardiol 1993;72:19A-26A.

9. Saul JP, Ross B, Erickson CC, Beerman L, Karpavich PP, Melikian AP, et al. Single dose pharmacokinetics of sotalol in a pediatric population with supraventricular and/or ventricular tachyarrhythmia. J Clin Pharmacol 2001;46:3543.

10. Berlex Laboratories, Inc. Internal Report No. 99009.

11. Schwartz GJ, Brion LP, Spitzer A. The use of plasma creatinine concentration for estimating glomerular filtration rate in infants, children and adolescents. Pediatr Clin North Am 1987;34:571-90.

12. Mosteller RD. Simplified calculation of body-surface area. N Engl J Med 1987;317:1098.
13. Bazett HC. An analysis of the time-relations of electrocardiograms. Heart 1920;7:353-70.

14. Fredericia LS. Die Systolendauer im Elektrocardiogramm bei normalen Menschen und bei Herzkranken. Acta Med Scand 1920;53:469-88.

15. Shi J, Ludden T, Melikian A, Gatonguay MR, Hinderling P. Population pharmacokinetics and pharmacodynamics of sotalol in pediatric patients with supraventricular or ventricular tachyarrhythmia. J Pharmacokinet Pharmacodyn. In press 2001.

16. Morselli PL, Franco-Morselli R, Bossi L. Clinical pharmacokinetics in newborns and infants: age related differences and therapeutic implications. Clin Pharmacokinet 1980;5:485-527.

17. Kearns GL, Reed MD. Clinical pharmacokinetics in infants and children: a reappraisal. Clin Pharmacokinet 1987;17(suppl):29-87.

18. Shammas FV, Dickstein K. Clinical pharmacokinetics in heart failure, an updated review. Clin Pharmacokinet 1988;15:94-113.

19. Woosley RL. Pharmacokinetics and pharmacodynamics of antiarrhythmic agents in patients with congestive heart failure. Am Heart J 1987;114:1280-90.

20. Ochs HR, Grube E, Greenblatt DJ, Arendt R. Intravenous quinidine in congestive cardiomyopathy. Eur J Clin Pharmacol 1981;19:173-6.

21. Ochs HR, Greenblatt DJ, Knuechel M. Oxaprozin pharmacokinetics in patients with congestive heart failure. Arzneimittelforschung 1986;36:1837-40.

22. Massarella JW, Silvestri T, DeGrazia, Miva B, Keefe D. Effect of congestive heart failure on the pharmacokinetics of cibenzoline. J Clin Pharmacol 1987;27:187-92.

23. Azzolini F, Catto G, Iaciutti G, Pelosi G, Picca M, Pocchiari $\mathrm{F}$, et al. Ibopamin kinetics after single oral dose in patients with congestive heart failure. Int J Clin Pharmacol Ther 1988;26:105-12.

24. Scott AK, Webster J, Petrie JC, Bastain W. The effect of age and cardiac failure on xamoterol pharmacokinetics. Br J Clin Pharmacol 1988;25:165-8.

25. Tisdale JE, Rudis MI, Padhi D, Borzak S, Svensson CK, Webb CR, et al. Disposition of procainamide in patients with chronic congestive heart failure receiving medical therapy. J Clin Pharmacol 1996;36:35-41.

26. Pai GR, Rawles JM. The QT interval in atrial fibrillation. Br Heart J 1989;61:510-3.

27. Reuning RH, Geraets DR. Digoxin. In: Evans WE, Schentag JJ, Jusko WJ, editors. Applied pharmacokinetics: principles of therapeutic drug monitoring. 2nd ed. Spokane (WA): Applied Therapeutics; 1986.

28. Roden DH. Antiarrhythmic drugs. In: Hardman JG, Limbird LE, editors. Goodman \& Gilman's the pharmacological basis of therapeutics. 9th ed. Vol 36. New York: McGraw Hill; 1996. p. 35-41.

29. Belz GG, Doering W, Munkes R, Matthews J. Interaction between digoxin and calcium antagonists and antiarrhythmic drugs. Clin Pharmacol Ther 1983;33:410-7. 
30. Brown HC, Carruthers SG, Kelly JG, McDevitt DG, Shanks RG. Observations on the efficacy and pharmacokinetics of sotalol after oral administration. Eur J Clin Pharmacol 1976;9:367-72.

31. Wang T, Bergstrand RH, Thompson KA, Siddoway LA, Duff HJ, Woosley RL, et al. Concentration dependent pharmacologic properties of sotalol. Am J Cardiol 1986;57:1160-5.

32. Le Coz F, Funck-Brentano C, Poirier J, Kibleur Y, Mazoit FX, Jaillon P. Prediction of sotalol-induced maximum steady-state QTc prolongation from single-dose adminis- tration in healthy volunteers. Clin Pharmacol Ther 1992; 52:417-26.

33. Kimura M, Umemura K, Ikeda Y, Kosuge K, Mizuno A, Nakanomyo $\mathrm{H}$, et al. Pharmacokinetics and pharmacodynamics of $( \pm)$ sotalol in healthy male volunteers. Br J Clin Pharmacol 1996;42:583-8.

34. Barbey JT, Sale ME, Woosley RL, Shi J, Melikian AP, Hinderling PH. Pharmacokinetic, pharmacodynamic, and safety evaluation of an accelerated dose titration regimen of sotalol in healthy middle-aged subjects. Clin Pharmacol Ther 1999;65:91-9.

\section{Receive tables of contents by E-mail}

To receive the tables of contents by E-mail, sign up through our Web site at

$$
\text { http://www.mosby.com/cpt }
$$

Choose "E-mail Notification."

Simply type your E-mail address in the box and click the "Subscribe" button.

Alternatively, you may send an E-mail message to majordomo@mosby.com. Leave the subject line blank and type the following as the body of your message:

$$
\text { subscribe cpt_toc }
$$

You will receive an E-mail to confirm that you have been added to the mailing list. Note that table of contents E-mails will be sent out when a new issue is posted to the Web site. 